\title{
O siso dO Meu Poeta: o riso do meu autor
}

\author{
Jane Tutikian \\ Universidade Federal do Rio Grande do Sul
}

RESUMO: A PARTIR DA OBRA DE GERMANO ALMEIDA, O MEU POETA, REFLETE-SE SOBRE AS QUESTÕES DE IDENTIDADE (POLITICA E CULTURAL) DE CABO VERDE.

ABSTRACT: BASED ON THE WORK BY GERMANO ALMEIDA, O MEU POETA, A REFLECTION ABOUT THE QUESTIONS OF IDENTITY (POLITICAL AND CULTURAL) FROM CAPE VERDE IS CARRIED OUT.

PALAVRAS-CHAVE: LITERATURA CABOVERDIANA, GERMANO ALMEIDA, O MEU POETA. KEY-WORDS: CAPE VERDIAN LITERATURE, GERMANO ALMEIDA, O MEU POETA. 
história de Cabo Verde é peculiar, ela remete, em sua origem, a uma variedade étnica e a uma sociedade multirracial relacionada por uma mistura lingüística de que se tomou o crioulo como língua oficial e remete, no presente, à estagnação imposta pela insularidade e características geofísicas, expressa na sobrevivência de uma sociedade regida por valores arcaicos.

A falta de recursos, a pobreza do solo, a pequenez das ilhas e a irregularidade das chuvas, tudo fez com que os portugueses não tivessem interesse de investimento. Aí, por exemplo, não se tentou introduzir a descaracterização regional, ainda que Portugal estivesse sob o fascismo salazarista e Cabo Verde sofresse esse mesmo fascismo numa situação colonial.

Neste momento, Gabriel Mariano (1991) refere dois movimentos opostos, o ascendente, aristocratizante, de negros e mulatos em contato com a cultura de língua portuguesa, e o descendente, democratizante, das "elites da terra" que difundiram as coletividades e as instituições culturais desse contato. Há, portanto, uma História de unidade na diversidade e de harmonização de antagonismos.

Conforme Pierre Rivas (1985, p.294), "la miscégénation fait du Cap-Vert, au sein des societés créoles, un cas d'acculturation exceptionnelle "um décentrement initial et fondateur" (Jean Benoist), décentrement entre créole et portugais, entre deux registres de l'être, du monde et des pratiques discursives, deux pôles (métaphorique et métonymique)." Se a "terra trazida"1 não é terra de origem, não é terra herdada, tampouco conquistada, seu povo termina assumindo características bem distintas daqueles das demais ex-colônias de expressão portuguesa na África: é a terra do temperamento da amorabilidade ${ }^{2}$, de um outro tipo de escravidão que ultrapassa a relação colonizador/colonizado para sucumbir à força escravizadora da própria terra. É onde o sonho passa a força revitalizadora, dentro do princípio de Manuel Lopes, autor do primeiro texto ficcional caboverdeano, de que o homem está ligado a fatores exteriores, os sonhos, às razões práticas. É onde se instaura o grande dilema do habitante do arquipélago: o ter de partir querendo ficar e o querer partir

1 Expressão utilizada por Manuel Ferreira em Hora di bai

2 O temperamento amorável, pacífico e solidário que caracteriza o ilhéu. Salvato Trigo definiu assim o caboverdeano: o grogue, a morna e a cabra. 
tendo de ficar, porque se estabelece entre a terra e o homem uma perfeita simbiose, sem possibilidade de cisão.

Esse dilema faz parte da estrutura mental do arquipélago. Como quer Pierre Rivas $(1985,292)$, a insularidade e o desenraizamento constituem duas estruturas antagônicas da identidade caboverdeana, "l'île, elle-même apparaît comme un abandon physique du continent maternel", daí a transformação desta insularidade geográfica em insularidade existencial. É a ilha, circunstância imediata, e uma pátria colocada num ponto utópico. 'Les littératures aliénés trouvent leurs paradigmes culturels ailleurs qu'en elles-mêmes. L'identification au Père, dans ces littératures ex-colonisées, est celle du Père colonisateur Blanc; c'est pourquoi, souligne R. Bastide, ces littératures sont marquées au départ du stigmate de l'imitation."

O estigma da imitação aproxima da identificação com o Brasil, sobretudo o Nordeste e seu circunstancialismo, promovida pela Claridade (1936), ou o próprio enraizamento voluntário ao continente africano, através da proposta da Certeza (1944) e da visão que imprime por influência do Neo-Realismo português, não anulando, entretanto, a evolução da experiência estética.

É bem verdade que Cabo Verde, hoje, uma república independente desde 05 de julho de 1975, tem uma outra realidade política e histórica diferente do período de colonização, mas uma realidade que traz no seu bojo todo um longo trajeto, passando por questões étnicas, geográficas, culturais e políticas. Aí, se destaca o PAIGC (1956), Partido Africano da Independência da Guiné e Cabo Verde, pelas teses do pensador membro da minoria caboverdeana na Guiné, Amílcar Cabral, quando anunciava que cultura não é sinal de libertação, libertação, sim, é sinal de cultura. Tudo isso representa um sofrido processo de conscientização cultural e nacional, até porque as independências políticas e econômicas normalmente precedem a independência cultural que instaura, em última análise, a própria busca da identidade nacional.

É importante assinalar, aqui, que a história da libertação da Guiné-Bissau e de Cabo Verde se confunde porque a grande maioria dos povoadores iniciais do arquipélago eram oriundos daquela ex-colônia e a transformação da luta anticolonialista em luta oficial e armada, em 1956, através do PAIGC, estreitou ainda mais esses laços.

Na luta pela libertação, o PAIGC se une ao MPLA, formando a Frente Revolucionária Africana para a Independência Nacional, a FRAIN. É com os 
dirigentes do PAIGC que acontecem, em Dacar, as primeiras reuniões formais para dar início à fase de transferência de poder, após a Revolução dos Cravos, em Portugal. Imediatamente o PAIGC propõe, para que essas negociações tenham êxito, o reconhecimento da Guiné como Estado independente e o direito à autodeterminação e independência de Cabo Verde. O acordo sobre Cabo Verde foi assinado em Lisboa, em 19 de dezembro de 1974, fixando o 5 de julho de 1975 para a declaração formal da independência. Em Cabo Verde, a transição, ao contrário de outras colônias, foi relativamente fácil.

Ao referir-se ao arquipélago, hoje, afirma Germano Almeida (1998) que

Cabo Verde é um país que tem sido, até agora, obrigado a sobreviver à custa do comércio, e sabemos que o comércio não aumenta a riqueza. Continuamos a pensar Cabo Verde como uma terra de agricultura mas são muitos mais os anos de estiagem: quando temos chuva ela só cai durante três meses por ano, e em geral não temos chuva nenhum tempo. Assim, a sobrevivência é só através do comércio.

Diz ele ainda:

Estamos dependentes da emigração. Somos um país muito dependente de reservas mandadas do exterior. Agora como antigamente: é um fenómeno de sempre, o da espera das poupanças enviadas aos familiares. O próprio comércio não seria suficiente para a sobrevivência das ilhas se não fosse este fluxo de moeda estrangeira. Esta rotatividade, que se dá também entre as ilhas, tem sido uma constante."

Nesse contexto, há o temor pelo futuro do país, na medida em que as ajudas internacionais são cada vez mais escassas.

No quadro mais geral da literatura luso-africana, tem-se que é a partir de 1936 que a literatura realizada em Cabo Verde começa a caminhar em direção a uma organização sistêmica, com o movimento decisivo que foi a Claridade, inspirado na revista homônima criada por Jorge Barbosa, Baltasar Lopes e Manuel Lopes. O movimento propunha o deslocamento de uma visão européia para o passado do arquipélago, ao mesmo tempo em que recusava a tradição portuguesa. Procurava assumir a modernidade, sobretudo a realista, a busca das 
raízes antropológicas e culturais, manifestada no gosto pela etnografia e filologia do crioulo e, ainda, a valorização da criatividade popular. Apontava, dessa forma, a descoberta de um espaço marcado pela insularidade, pela fome, pela seca, pelo mar feito prisão e caminho de uma cultura essencialmente mítica.

Guiados pelo Modernismo brasileiro e baseados na semelhança com o Nordeste, os seguidores da Claridade "encararam a independência política brasileira como factor de relevo para a assunção de uma literatura própria, nacional, e reconheceram a necessidade do regionalismo como primeira condição para fugir à ditadura literária da metrópole européia.”(LARANJEIRA, 1992, p.23)

O conceito regional da Claridade é substituído pelo conceito nacional da geração que a seguiu: a da Certez̧a, de 1944, que, sob a influência do Neo-Realismo português, do romance regionalista nordestino brasileiro e da introdução de uma visão dialética marxista, adentra por uma concepção nova do coletivo. Nela, a Segunda Grande Guerra tem papel de grande importância, na medida em que recusa o restrito e o tribal, colocando em seu lugar a luta pela inserção de Cabo Verde, como nacionalidade, dentro do contexto africano. Há a percepção de que o destino histórico e político do arquipélago está intimamente vinculado ao contexto africano.

A ruptura propriamente dita em relação à tradição "claridosa" é [...] ensaiada mais tarde nas páginas do boletim Cabo Verde, publicado na cidade da Praia, no qual Amílcar Cabral fizera, em 1952, apelo a uma literatura politicamente mais empenhada e onde Gabriel Mariano e Ovídio Martins, desta feita no primeiro e único número do Suplemento Cultural do referido boletim, saído em 1958, publicaram poemas onde era notória a influência do movimento nacionalista que, nessa altura, dominava a vida política e social do continente africano. Um ano depois, em 1959, coube aos que deram voz ao Boletim dos Alunos do Liceu Gil Eanes percorrer, a partir do Mindelo, os mesmos trilhos estético-políticos. O antievasionismo acentua-se com essa geração. "Gritarei / Berrarei / Matarei / Não vou para Pasárgada”, versos de Ovídio Martins, confirmam-no. Mas mais. Com esses jovens, certamente por impulso de Amílcar Cabral, o rumo da caboverdeanidade, enquanto interpretação do destino caboverdeano, começa a passar por África, pelo continente africano . Conseqüentemente ganha expressividade a dualidade entre a tradição estético-política inaugurada pelos "claridosos" e, 
de certa forma, continuada pelos da "geração de 40", e a posição da "geração de 50", no fim, a "geração nacionalista", [...] vindo muitos dos seus elementos a integrar as fileiras do Partido Africano para a Independência da Guiné e Cabo Verde - PAIGC, o movimento que conduziu, quase que exclusivamente, a luta de libertação nos dois países.

Entretanto Teixeira de Sousa manteve acesa até aos anos 90 a chama da Certeza. É, após a independência e, pelo menos, durante uma década, o romancista caboverdeano de referência. (ALMEIDA, 1998)

Ao lado do Cabo Oficial (1949), do Suplemento Cultural (1958), do Seló (1962), do Raíges (1977), pode-se falar do Ponto \& Virgula (1983) no processo de desenvolvimento cultural do arquipélago, mas eles vêm, ainda, no ideário daqueles dois movimentos: Claridade e Certeza. O que, segundo Manuel Ferreira (1997, p.28) "não invalida que, para além das eventuais ou possíveis subdivisões, não venha a considerar-se a literatura caboverdeana em duas grandes fases: antes e depois da Claridade."

Germano Almeida, com Rui Figueiredo e Leão Lopes, foi fundador da revista Ponto \& Virgula (março de 1983 a dezembro de 1987), do jornal Aguaviva, de que era co-proprietário. Se, aí, iniciou a publicação de seus contos, foi também na revista que publicou fragmentos de O Meu Poeta.

[...]É verdade que continuamos a dormir à sombra dos louros da «Claridade», como se isso nos bastasse. Não tentamos ultrapassar, continuar a experiência «claridosa». E nem houve ruptura entre essa geração e as actuais; a viagem literária que eles fizeram fi-la eu 50 anos depois, veiculado a um meio mais urbano... (ALMEIDA, 1998)

Apesar dessa declaração, é importante observar que o escritor, mesmo sem romper com a tradição, vai além do Movimento Claridoso, sim. Deve-se a ele a revelação de uma nova face da literatura caboverdeana, na medida em que, distanciando-se dos temas eixos daquele movimento, como a fome, a seca e a emigração, ( tão evidenciados em Cabo Verde-Viagem pela História das Ihas, obra de 2003, onde revela o sofrimento e a resistência do povo) introduz o humor - e muitos o consideram verdadeiro cultor da ironia do Mindelo - na literatura caboverdeana. 
É através do humor e da sátira que traz à literatura a visão de uma sociedade asfixiada durante os primeiros anos de independência por um partido único. Exemplar, neste sentido, é O Меи Poeta (1990), considerado o primeiro romance verdadeiramente nacional da nova República de Cabo Verde.

Nessa obra, o autor confirma a inovação estética já anunciada em $O$ Testamento do Sr. Napumoceno da Silva Araíjo (1989), saudado pela crítica como um dos grandes momentos da literatura caboverdeana atual, onde narra a história de um homem que conseguiu enriquecer, vendendo 10 mil guarda-chuvas, numa terra cujo principal problema é a seca permanente.

Em O Meи Poeta, o autor faz um retrato satírico dos governantes e das elites culturais caboverdeanas, no pós-colonialismo, criticando, também, o entendimento da cultura e da literatura pelo viés político.

Tomemos três pressupostos básicos:

1. Se a fixação do nacionalismo colonial caracteriza-se pelo anticolonialismo, também é certo que ele guarda em si um forte apelo imitativo, até porque, segundo Bhabha (1998, p.70), retomando Fanon, o tempo da libertação pode ser definido como um tempo de incerteza cultural e "mais crucialmente, de indecibilidade significatória ou representacional." E, some-se a isso, o fato de que a identidade é a produção de uma imagem de identidade e de transformação do sujeito ao assumir aquela imagem (Idem. p.76) e, mais ainda, querendo ou não, num primeiro momento, a identidade está inscrita no signo da semelhança.

2. Se a identidade nacional é a melhor e maior forma de reconhecimento coletivo, então, é verdadeira a afirmação de Anthony D. Smith (1997, p. 197) de que a sua função primordial é a de proporcionar uma forte 'comunidade de história e destino’ para salvar as pessoas de um esquecimento individual e para restaurar a fé coletiva. Nessa perspectiva, o nacionalismo pode ser definido como uma ideologia política que tem como centro uma doutrina cultural. Assim, a identidade nacional é composta de uma identidade política e de uma identidade cultural e, ainda segundo o autor, tem sua localização quer numa comunidade política, quer numa comunidade cultural.

3. Se a cultura nacional é um discurso, de acordo com o pensamento de Hall (2004), então, as culturas nacionais, além de serem compostas por instituições culturais, também o são por símbolos e representações. 
Importam essas colocações porque, ao traçar o "perfill" do "Meu Poeta", a personagem, caricato mediador político-cultural, a partir da luta pela reabertura do "Retiro Fechado", um bar elevado à categoria de instituição municipal, Germano Almeida vai trabalhar, através da paródia, justamente sobre os dois grandes constitutivos da identidade nacional: a identidade política e a identidade cultural de Cabo Verde.

O Meu Poeta é um livro escrito no momento em que vigia, no arquipélago, o chamado regime do partido único, o PAICV, o Partido Africano da Independência de Cabo Verde. O enredo gira em torno da eleição do poeta, um intelectual mindelense, para presidente da "Comissão de Luto Municipal" criada quando do encerramento do bar "Retiro Fechado". Assim, atingindo certa notoriedade, o poeta acaba por fazer dispersar, num discurso carregado de equívocos, uma manifestação jovem de protesto político. É entrevistado na rádio local. Publica a "Ode à Baía das Gatas". E torna-se "embaixador itinerante da cultura caboverdeana".

É através da trajetória do poeta que o autor coloca em cena o ambiente sócio-político e moral das elites caboverdeanas, responsáveis pela derrocada da Primeira República. Aparecem, aí, as discussões políticas, as ambições mesquinhas, a degradação moral, os enganos amorosos e os jogos de sedução, e o grande contra-ponto instaurado pela criação de uma personagem lúcida como Vasco. É como joga um Cabo Verde real, constituído por uma sociedade marcada pela estagnação, uma quase caricatura, contra um Cabo Verde ideal, talvez uma possibilidade, produzindo uma análise paródica daquela sociedade do pós-independência.

Do ponto de vista da estrutura narrativa, a obra situa-se no plano do real objetivo, inserindo-se dentro da crônica social urbana. Há o alinhamento de episódios, não necessariamente em ordem cronológica, em que os capítulos são introduzidos por motes, a exemplo do cordel. Note-se que o cordel é originário da Península Ibérica, guardando um caráter fortemente popular, onde o autor se torna um repórter da vida cotidiana, tal qual em O Meu Poeta, quando se faz a reportagem dos acontecimentos na vida caboverdeana. Seu estilo é o de uma prosa fluente, de períodos longos, de registro oralizante, utilizando, em abundância, como recurso, chavões políticos ou ditados populares.

Chamado a escrever o perfil do "Meu Poeta" por uma editora, uma exrevolucionária e grande paixão do narrador (ao falar dela, é o único momento 
em que se permite um certo lirismo), ele, o secretário do Poeta, passa a escrever para ela, contando o que conta no livro. Assim, o livro que chega ao leitor é o que ele conta do livro do qual é autor e não o livro mesmo, recurso este que dá a Germano Almeida, total liberdade na fixação de personagens e na discussão de idéias político-sociais e estéticas, discutindo, inclusive, a criação do próprio texto.

Este narrador, sem nome, autor do livro do qual conta e narrador do que conta, o relato do livro - o livro que chega ao leitor -, assume o estatuto de narrador não digno de confiança, dentro da concepção de Wayne Booth (1980), retomada por Paul Ricoeur (1997). Ele, de fato, desordena as expectativas do leitor e o seduz na medida mesmo em que instaura a desconfiança.

Aí, o narrador de Germano Almeida transita com igual liberdade entre a ficção e a realidade, uma vez que Cabo Verde, sua história e sua tradição estão lá, confrontando-as, dando à obra um tom de "artesanato ficcional" que se constrói na própria leitura, consciente de que "quem conta um conto acrescenta um ponto”( OMP, p.104). Para Booth (1980), a utilização deste narrador está intimamente ligada ao mundo caótico representado na narrativa.

E, como na obra do escritor caboverdeano, este narrador está numa posição de ulteridade, até porque o narrado é do passado, de uma década depois da independência, termina assumindo a condição demiúrgica efetiva. Tudo passa por este narrador, nada lhe escapa, inclusive a discussão sobre a sua própria criação, sobre as possibilidades de descrição dos seus seres fotografados e seu futuro, sobre a reversibilidade temporal, sobre a associação do texto a outro texto, como a inserção dos escritos de Vasco, sobre a intertextualidade no chamamento de grandes ficcionistas e poetas da literatura caboverdeano e internacional.

$\mathrm{E}$, ao mesmo tempo em que reflete e discute o que faz e como o faz com alguém que não responde, uma espécie de diálogo com o interlocutor ausente, estabelecendo a diatribe bakhtiniana, oferece, ao autor real, a possibilidade de avaliação daquele funcionamento social. E o faz através da parodização da sociedade, da política e do comportamento intelectual, mas também, através de um processo de auto-reflexibilidade desmitificadora do conhecimento estético. Esta é, na verdade, a grande arma utilizada por Germano Almeida, lançando mão da exageração irônica e caricatural em todo esse processo de reavaliação que, em última análise, se encaminha para a reavaliação da identidade caboverdeana. 
A grande paródia social de Germano Almeida, se faz através do Poeta, Deputado e Embaixador Itinerante da Cultura de Cabo Verde, reacionário ingênuo, sexualmente impotente, um tipo caricatural, que assume para si, teoricamente, a paráfrase de Amílcar Cabral, o grande pensador da independência dos países africanos de língua portuguesa. "Sou apenas um modesto caboverdeano disposto a dar o meu modesto contributo para a reconstrução da minha terra. Não são cargos ou honrarias que eu busco. Desejo apenas servir o melhor que posso e sei." (OMP, p. 196)

Ela se inicia pelo fechamento "abusivo" "Retiro Fechado". O fato quase provoca uma revolta pequeno-burguesa, suscitando, primeiro, o desejo de luto nacional com bandeira a meio pau em todo o país, uma vez que a casa já podia ser considerada uma instituição de caráter nacional, uma fundação destinada ao bem-estar daquela classe, e, depois, de uma forma mais conveniente, luto municipal.

[...] o meu poeta tinha o dom de arrebatar multidões e, como aliás era de se esperar, a sua proposta veio a merecer unânime consenso, especialmente quando ele avançou considerações da ordem e no sentido de que, sem dúvida, o Retiro Fechado é uma instituição, tal-qualmente uma fundação como tinha afirmado que era uma instituição de caráter regional e, pela sua essência e localização, primacialmente destinada a servir a pequena burguesia mindelense e apenas episodicamente a forasteira. Daí que me parece, concluiu, que, salvo melhor critério e opinião mais abalizada, o luto municipal é suficiente expressão de pesar, além do mais com a peculiar vantagem de mostrar um pesar local, devidamente circunscrito, não alongado a todo o país, não se vá pensar ser o Retiro Fechado um bem nacional, passível de ser reivindicado por qualquer um. (OMP, p.31)

Para Hutcheon (1989, p.42), a paródia provoca, de forma paradoxal, uma confrontação direta com o problema da relação do estético com o mundo de significação exterior a si mesmo, com um mundo discursivo de sistemas totalmente definidos (presente e passado), em outras palavras, com o político e o histórico. Assim, a paródia é, na sua "transcontextualização" irônica, usando expressão da autora, inversão, repetição com diferença, impondo uma distância crítica, marcada pela ironia, entre o parodiado e a obra que o incorpora. 
A paródia é, então, transgressão, em todos os sentidos, das formas artísticas, ainda que as utilize. Trata-se, portanto, de uma transgressão autorizada do próprio objeto estético, como, também, transgressão da apreensão da sua exterioridade, o objeto real. "[...] Assumindo uma atitude contra-ideológica, na faixa do contra-estilo, a paródia foge ao jogo de espelhos denunciando o próprio jogo e colocando as coisas fora de seu lugar "certo", comenta Sant'Anna. (1995. p. 29)

É através da posição de refração à ideologia dominante, que os valores e elementos essenciais de caboverdeanidade vão sendo trazidos à narrativa.

A questão política é esvaziada pelo absurdo da origem do conflito: o fechamento do bar, pelas situações inusitadas e pelos discursos, sobretudo os do Poeta, carentes de sentido prático, mas, também, neste jogo que o narrador propõe construir no limite entre a ficção e a realidade, traduzindo-se em uma crítica exacerbada ao sistema de partido único, "força, luz e guia do nosso povo na Guiné e em Cabo Verde, [...] formado pelos melhores filhos do nosso povo, encarnação dos supremos ideais dos povos da Guiné e de Cabo Verde, na unidade das duas nações africanas separadas pelo racismo colonial fascista" (OMP, p.37) Há, entretanto, o golpe de Estado de 14 de novembro de 1985 na Guiné Bissau, e a conseqüente ruptura do binacionalismo Surge o PAICV, herdeiro do PAIGC, que não rompe completamente com uma epopéia de libertação nacional que lhe confere legitimidade política para continuar monopolizando toda a expressão política.

Da regência deste partido único emana a confusão entre independência e liberdade, quando a primeira é um meio e a segunda um fim. Daí a indagação : "Nós, por exemplo, somos independentes. Mas somos livres? Os políticos afirmam nossa liberdade. Mas o povo conhece-a, sente-a, vive-a?” (OMP, p. 173)

A discussão da liberdade é proposta pelo viés irônico, na medida em que ela é construída pelo contraditório, pelo inusitado. Aí, ela é colocada em primeiro plano, na forma de balanço histórico, em relação à juventude.

Diante de uma manifestação dos jovens mindelenses em memória de John Lennon, diz o Poeta:

Afinal, disse ele, não sabes e não entendes o que é a dialéctica, porque se soubesses verias que há doze anos adquirimos a liberdade de pensar que durante 500 anos nunca tivemos. E quem lutou, morreu e deu a vida por isso? Foram 
eles, os jovens? Não, sabes que não. Fomos nós que lutámos contra a pide, que sofremos as prisões e perseguições do fascismo colonial r que pelo esforço da nossa luta chegámos à vitória. Eles o que são é uns felizardos que mal conheceram o fascismo e a repressão. Naquela época é que não tínhamos nenhum tipo de liberdade, nem de brincar o carnaval nem brincar a tabanca. Mas tu és testemunha que uma das primeiras medidas tomadas após a independência foi justamente repor a tabanca, o carnaval e outros folguedos tradicionais injustamente proibidos pelo regime colonial. Que mais liberdade de expressão eles precisam? (OMP, p. 80)

Ora, ao mesmo tempo em que se evidencia a urgência de resgate da tradição, seja pelo carnaval, seja pela tabanca, frutos da necessidade significatória e representacional de uma (re)construção identitária, se evidencia o primeiro pressuposto colocado ao início desta parte do trabalho: a fixação do nacionalismo colonial caboverdeano, tal qual colocado, tem uma postura anticolonial, ainda que guarde em si um forte apelo imitativo.

[...] eu respondi-lhe que, daquilo que eu ouvira, tinha entendido que os jovens se preocupavam com questões como o emprego, a escola, a própria salvaguarda do país e que nesse sentido queriam participar nessa democracia e que reivindicavam a liberdade de expressar os seus pontos de vista...[...] Mas o Meu Poeta atalhoume [...] Liberdade de expressão, dizes tu? Então já não têm o suficiente? O que de facto precisam é de cadeia, pau, polícia atrás deles. (OMP, p.80)

Trata-se, enfim, segundo o Poeta, representante da intelectualidade e de seu pensamento, de uma "juventude alienada e transviada que não conhecendo o seu passado, não dominando o presente, quer construir o futuro."( OMP, p.65) Rouba-se-lhe, portanto, na democracia, tal qual o fascismo roubou, a possibilidade de decisão sobre seu próprio futuro, até porque há o reconhecimento de que "a nossa formação ideológica é toda ela fascista e o fascismo instalou em nós quer a dependência e submissão perante os que estão acima quer, por outro lado, o autoritarismo e rispidez para os que estão abaixo." (OMP, p. 190)

É em situações aparentemente despretensiosas que Germano Almeida estabelece o contraponto, a leitura séria de Cabo Verde jogada contra um riso 
que, parafraseando Kristeva (1974), torna-se um riso sério e este contraponto é centrado no discurso de Vasco.

À crença do Poeta de que a burguesia que ascendera ao poder, tal qual preconizara Cabral, após a independência se suicidara como classe entregando-se aos interesses da massa, Vasco contrapõe a demonstração de que o aburguesamento e o afastamento dos dirigentes dos problemas daquelas, com que se haviam comprometido. E quando Vasco se refere ao meio, ele se refere à miséria, à doença, à falta de trabalho, ao analfabetismo. Mas fala, também, de um povo acomodado, que ainda não descobriu que a "participação não se oferece, conquista-se.” (OMP , p. 117) e que, no máximo, gosta de improvisar, "não programar as coisas como branco faz." (OMP , p. 153)

Sendo a cultura fonte da identidade e sendo a literatura forte elemento de resistência da identidade nacional, a literatura caboverdeana é profunda e criticamente exposta através do protagonista. É de salientar e, aqui, a força da tradição, que o Poeta escrevia em português e em crioulo (OMP, p. 42), tal qual convinha aos grandes autores da época colonial de afirmação de uma identidade, tanto da Claridade quanto da Certeza.

A grande crítica à literatura caboverdeana é a da estagnação, e, aí, Germano Almeida vai a um dos elementos mais caros à tradição literária caboverdeana, a verdadeira "instituição" nacional: o Movimento Claridoso, quando, ao alertar sobre a passividade da sociedade, e a necessidade de escrever sobre ela, deparase com a existência, talvez, de um homem novo, o do pós-independência, que deveria produzir uma nova literatura que, de fato, não há.

Meu Poeta retoma a simbólica da cultura caboverdeana e a desfaz, transformando pasárgada em "plágio grosseiro e descomedido", aludindo ao poeta claridoso Osvaldo de Alcântara, ou um simples "poema tuberculoso", referindo a Manuel Bandeira. Há, então, o balanço irônico e desmistificador: a geração claridosa é tomada como a "geração que foge da luta do seu povo." Para esta geração da reconstrução nacional, ir para pasárgada significa "escolher ficar longe do seu povo e melhor servir o Partido porque na Pasárgada falará da lua, do mar, das flores, mas já lá não verás o homem humilhado, o homem sem pão, o homem estupidificado pela miséria.” (OMP, p.228) Pasárgada, tal qual a Claridade é, portanto, a alienação. "Agora, Cabo Verde é Praia e o resto são arredores, periferia, bairros de lata." (OMP, p. 245) Mindelo é um porto agonizante. 
Assim, é através da paródia e da ironia que se dá o entrecruzamento entre a ideologia e a contra-ideologia promovendo-se, em conseqüência, a refração, a revisão crítica. Germano Almeida combina o que se nega e o que se afirma, promovendo a desmitificação. É o que Kristeva (1974) afirma como "cômico e trágico". E ele o faz resgatando a vida individual cotidiana, abrindo-a para uma perspectiva coletiva, revisando, criticamente, as identidades política e cultural caboverdeanas, alicerces da identidade nacional e do nacionalismo, ao dessacralizar suas instituições, símbolos e representações. É a proposição de um novo tempo: um novo ver-se e um ver Cabo Verde com outros olhos: os críticos, os da ruptura com o velho, com o "cotidiano oficial".

O que o escritor caboverdeano faz é devolver à personagem Dura, devolvendo, assim, aos caboverdeanos, o que ela diz sentir falta: "passados tantos anos sobre a independência, ainda ninguém se abalançou a tentar traduzir em termos literários esta vivência, esta nova realidade em romances, novelas ou simples contos. Até agora tem sido como se ainda estivéssemos na noite colonial." (OMP, p. 163) E ele o faz como um grande espelho invertido, aliás, ele o faz tanto nesta obra como em Eva, obra de 2006, que faz um balanço da independência 20 anos depois.

É importante ressaltar que tanto a mímica do ponto de vista de Bhabha (1998), com o carnaval bakhtiniano (1993 (b)), são ambíguos, marcados pelos excessos, e evidenciam uma recusa: criam uma realidade em que repetem e, simultaneamente, refratam a realidade mesma, uma realidade que é produto da paródia e da ironia, que por si só são também ambíguas, na medida em que afirmam o que não querem dizer, ou afirmam o contrário do que querem dizer, sendo, portanto, uma linguagem pervertida. E, sendo "um espelho invertido", a criação paródica representa a libertação do discurso e uma tomada de consciência crítica. É quando se promove a desmitificação e dessacralização de valores nacionais aparentemente estáveis.

Ora, se o pós-independência é o tempo da incerteza e da indecisão "significatória e representacional" e se a elas estão atreladas à própria fixação do nacionalismo, então, o deslocamento da soberania, que antes residia nos símbolos portugueses, para os novos símbolos de uma identidade emergente, exige uma reinterpretação dos velhos paradigmas, na medida mesmo em que, como quer Bhabha (1998), a identidade é a produção e assimilação de uma imagem de identidade. 
Mais ainda, sendo a identidade nacional constituída por uma identidade política e por uma identidade cultural, elas estão localizadas numa comunidade política e numa comunidade cultural, por sua vez compostas por instituições, símbolos e representações.

É o que Germano Almeida vai buscar, na essencialidade caboverdeana, e expor para reinterpretação. Para isso, ele aponta para uma sociedade que colocou em causa seus símbolos, valores sociais e mitos, sem que fossem substituídos. Aí, o autor propõe a desmitificação geral do próprio processo de remitificação, a partir da apreensão da realidade pelos grupos ingenuamente realistas - representados pelo Poeta - encontrando neles mesmos seu princípio explicativo, além da sacralização ideológica em que colocam a identidade pela negação ou camuflagem das contingências históricas, o que implica a repetição ad infinitum de discursos anacrônicos e populistas.

Assim, o "Retiro Fechado" é elevado a uma condição mítica, sacralizado como instituição municipal ou nacional, porque os mitos foram derrubados e as instituições dessacralizadas.

É Vasco, não gratuitamente o defunto, afinal, a história tem que seguir seu curso, quem explica:

[...] Só que, após a independência, o Partido, em vez de fazer o que se esperava ele fizesse, Isto é, abater a burguesia, aproxima-se dela, alia-se a ela, faz na prática a política dela, mantendo embora um discurso populista que por algum tempo ainda desnorteou as pessoas. (OMP, p.189)

Sobram, então, ainda resquícios de uma identidade assentada sobre o servilismo, alimentada e realimentada pela dependência do exterior, a desses "filhos deserdados desta pátria mártir, duas vezes afastados do seu berço pela insularidade e pelo colonialismo". (OMP, p. 287) Mas, sobretudo, sobram o mito da morabeza, o grogue, a morna e nada mais nacional do que eles, esconderijos de premissas da identidade que - e é o que Germano de Almeida vem dizer -, no período da pós-independência, precisa ser recriada neste espaço do vazio. 


\section{Referências bibliográficas:}

ABDALA JUNIOR, Benjamin.Crioulidade- Resistência e identidade nacionais nas literaturas africanas de língua portuguesa. In: $1^{\circ}$ Seminário Latino-Americano de Literatura Comparada. Porto Alegre: UFRGS, 1986.

ALMEIDA, Germano. O meu poeta: romance (uma terra sem amos). Lisboa: Caminho, 1992. ALMEIDA, Germano. O testamento do Sr. Napumoceno da Silva Araújo. Lisboa, Caminho, 1991. ALMEIDA, Germano. Cabo Verde - Viagem pela história das ilhas. Lisboa: Caminho, 2003.

ALMEIDA, Germano. Eva. Lisboa: Caminho, 2006.

ALMEIDA, Germano. Temo pelo futuro do meu país. Entrevista de António Loja Neves, In: Expresso, 12 de Setembro, 1998.

BAKHTIN, Mikhail. Questões de literatura e de estética. (A teoria do romance) Trad.Aurora Fornoni Bernadini e outros. 3.ed. São Paulo: Hucitec, 1993.(A)

BAKHTIN, Mikhail. A cultura popular na Idade Média e no Renascimento. O contexto de François Rabelais. Trad. Yara Frateschi Vieira. São Paulo: Hucitec/ Brasília: Editora da Universidade de Brasília, 1993. (B)

BHABHA, Homi K. O local da cultura. Trad. Myriam Ávila, Eliana Lourenço de Lima Reis e Gláucia Renate Gonçalves. Belo Horizonte: Ed. UFMG, 1998.

BOOTH, Wayne. The Rhetoric of Fiction. Chicago:University of Chicago Press, 1961.

CARVALHO, Alberto. Prefácio a Cultura caboverdeana: ensaios. Lisboa:Vega, 1991.

FERREIRA, Manuel. Literaturas Africanas de Expressão Portuguesa I. Amadora, Instituto de Cultura Portuguesa, 1977

FERREIRA, Manuel. Hora di bai. $3^{\mathrm{a}}$ ed. . - Lisboa : Plátano Editora : Atica, 1980.

HALL, Stuart. A identidade cultural na pós-modernidade. Trad. Tomaz Tadeu da Silva e Guaracira Lopes Louro. 9.ed. Rio de Janeiro: DP\&A, 2004.

HOUTCHEON, Linda. Uma teoria da paródia. Lisboa: Edições 70, 1989.

KRISTEVA, Julia. A palavra, o diálogo e o romance. In: Introdução à Semanálise. São Paulo: Perspectiva, 1974.

LARANJEIRA, Pires. De letra em riste: identidade, autonomia e outras questões na literatura de Angola, Cabo Verde, Moçambique e S. Tomé e Príncipe. Porto: Afrontamento, 1992.

MARIANO, Gabriel.Cultura caboverdeana: ensaios. Lisboa: Vega, 1991

RICOEUR, Paul. Tempo e Narrativa. Campinas: Papirus, 1997. V. III

RIVAS, Pierre. Insularité et deracinement dans la poésie capverdienne. In:Les literatures africaines de langue portugaise: à la recherché de l'identité individuelle et nationale. Actes du Colloque. Paris: Fondation Calouste Gulbenkian, Centre Culturel Portugais, 1985.

SANT'ANNA, Affonso Romano de. 5ed. Paródia, paráfrase \& cia. São Paulo: Ática, 1995. SMITH, Anthony D. Identidade Nacional. Lisboa: Gradiva, s.d.

TOMAS, António da Conceição. Germano de Almeida: "Não tenho a pretensão de escrever um romance". Público. Lisboa, 25 abr. 1998. 